WellBeing International

WBI Studies Repository

1976

\title{
The Nursing Posture of Domestic Sows and Related Behaviour
}

D. Fraser

University of Edinburgh

Follow this and additional works at: https://www.wellbeingintlstudiesrepository.org/reabeh

Part of the Animal Studies Commons, Behavior and Ethology Commons, and the Comparative Psychology Commons

\section{Recommended Citation}

Fraser, D. (1976). The Nursing Posture of Domestic Sows and Related Behaviour. Behaviour, 57(1), 51-63.

This material is brought to you for free and open access by WellBeing International. It has been accepted for inclusion by an authorized administrator of the WBI Studies Repository. For more information, please contact wbisr-info@wellbeingintl.org.

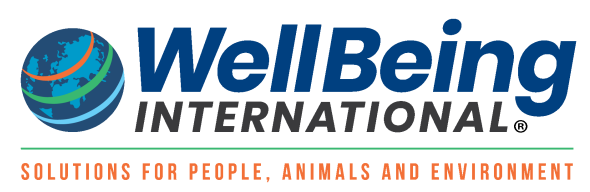




\title{
The Nursing Posture of Domestic Sows and Related Behaviour
}

\author{
D. Fraser
}

University of Edinburgh

\section{INTRODUCTION}

When a sow nurses its piglets it usually assumes a characteristic posture, lying on one side with the udder rotated exposing both rows of teats. The head is generally pushed back, and the upper legs may be held in the air. In addition the forelegs are commonly straightened and thrust backwards so vigorously that they may batter the piglets away from the anterior teats. The occurrence of such an elaborate nursing posture with some elements of dubious adaptive advantage, is somewhat puzzling. The issue is made more complex by the observation that a similar posture is sometimes assumed by sub-adult pigs of both sexes in response to stimulation of the belly by penmates (EWBANK \& MEESE, 1971; FRASER, 1974), or it may even occur spontaneously, apparently as a form of stretching after sleep.

Abnormalities in the nursing posture can pose a serious problem in pig husbandry. In particular some lactating sows do not rotate the udder sufficiently, leaving the lower teats inaccessible to the piglets. Furthermore sows sometimes refuse to adopt the nursing posture even in response to prolonged solicitation by the piglets. This may be associated with disease, injury to the udder, or other disturbance (e.g. RINGARP, 1960, p. 21), but is not always readily identified with any obvious factor. In view of both the scientific and practical problems associated with the nursing posture, a more detailed study of the behaviour appeared to be warranted.

Aspects of the saw's nursing behaviour have been studied experimentally by substituting manual rubbing of the udder for the stimulation provided by the litter of piglets (FRASER, 1973, 1975). Pregnant and lactating sows will assume the nursing posture when their udders are rubbed by hand, and will give the characteristic, rhythmic nursing grunts if the stimulation continues. However sustained grunting and milk ejection require that the stimulation be applied to the anterior end of the udder (FRASER, in press). Two issues arise from these observations. First, it is not clear whether the anterior-posterior difference in the sensitivity of the udder is specific to the milk ejection response and associated grunting, or whether other aspects of nursing behaviour, such as the preliminary rotation of the udder, are also selectively affected by anterior teat stimulation. Second, it is not known how the anterior-posterior difference arises. Is it, for example, confined to sows in late pregnancy and lactation, in which case it might be due to the teats' being engorged with milk to different degrees; or can evidence of such a difference be found in pigs in other states? 
The present paper describes a collection of experiments, carried out over a three-year period, in which different aspects of the pig's response to manual stimulation of the teat area were studied. The experiments on mature sows compared the circumstances under which an animal would or would not assume the nursing posture in response to manual stimulation of the udder, and studied the effectiveness of stimulation on the different teats for eliciting directed rotation of the udder. An experiment on juvenile male pigs similarly gave attention to the conditions under which the animals would or would not assume the nursing posture, and to the conditions for eliciting directed rotation of the udder. The effectiveness of anterior- and posterior-end stimulation for eliciting rhythmic grunting was also compared with these immature males. Finally, an experiment on suckling piglets studied the incidence of the various components of the nursing posture in response to gentle stimulation of the body surface.

\section{OBSERVATIONS ON PREGNANT SOWS}

Initial reactions to stimulation of the udder.

Method.

Observations were made on 49 pregnant sows of the Large White or Large White $\times$ Landrace breeds, mainly in the course of experiments reported elsewhere (FRASER, 1973). An estimated 3 to 7 days before parturition the animals were moved into individual pens measuring approximately $2 \times 3 \mathrm{~m}$, each with restraining rails to prevent the sows from lying on their eventual offspring. At least $24 \mathrm{~h}$ later the sows were tested for their reactions to manual stimulation of the udder. The experimenter entered the pen quietly, stroked the saw's neck for a few seconds, then gently rubbed the belly just lateral to the nearer line of teats, and finally massaged the udder and rubbed the teats for up to $5 \mathrm{~min}$. This procedure was usually repeated once daily until parturition. Written records were made of the animals' behaviour including (1) whether the sow was standing, sitting or lying down before the experimenter approached, (2) whether the animal changed position, moved about energetically, or grunted when the experimenter entered the pen, and (3) the reaction to stimulation of the udder as described below.

Results.

There were three main responses to stimulation of the udder. Some animals gave the "complete response", consisting of lying down (if previously standing), assuming the nursing posture with the teats exposed, and grunting rhythmically. Some pigs which we are standing initially merely rotated the udder toward the source of the stimulation; and some gave neither of these responses.

On the first day of testing, 24 of the 49 sows stood up or remained standing and moved about energetically, often grunting loudly, when the experimenter entered the pen. Of these, 2 gave the complete response to stimulation of the udder, 3 only rotated the udder, and 19 gave neither reaction. The other 25 sows remained fairly placid, with no changing of position when first approached. Of these, 13 gave the complete response, 5 only rotated the udder, and 7 gave no response. The sows which either rotated the udder or gave the complete response were combined to meet the requirements of the $x^{2}$ test, which showed that the animals which gave a placid initial reaction to the experimenter had a higher proportion of response to stimulation of the udder $(P<0.001)$. The original position of the animal (standing, sitting or lying) did not appear to influence the proportion responding.

Twenty-nine sows were tested on 3 or more days and gave the complete response to udder stimulation at least once. Fig. 1 shows the percentage of these animals which gave the complete response and the percentage which gave no response on the days before and after the first occasion that the complete response was given. For the most part, once an animal had given the complete response it rarely failed to do so on subsequent days. The response of rotating the udder was particularly common $(39 \%)$ on the two 
days before the complete response was given. There was no indication that the sows characteristically began to respond a particular number of days before parturition.

Fig. 1. The percentage of sows giving the complete response and those giving no response to stimulation of the udder during the days before and after the animals' first complete response, indicated by the vertical arrow.

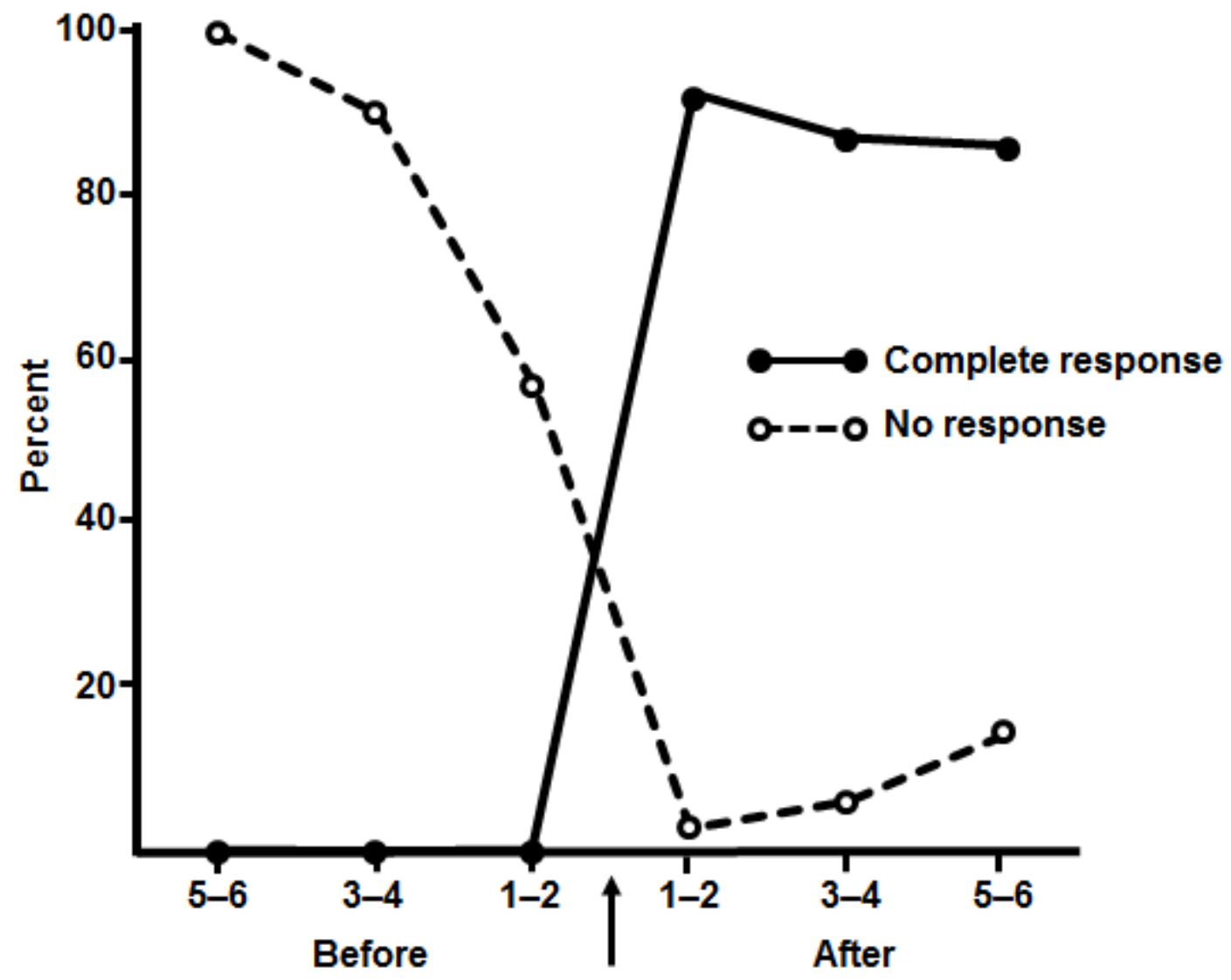

Rotation of the udder.

Method.

Eight sows in farrowing crates were used during late pregnancy in two studies of the rotation of the mammaries in response to manual stimulation of different parts of the udder. Each sow was tested at a time when it was lying on its side with the udder exposed. The experimenter entered the pen quietly, and placed beside the udder a flexible metal ruler held vertical by a heavy stand. The ruler was bent to fit approximately the curvature of the sow's belly. It was placed in line with either the third or fourth pair of teats from the anterior so that as the recumbent sow rotated its udder higher or lower above the floor, the upper third or fourth teat moved up and down the length of the upright ruler. The ruler was marked in 6 $\mathrm{mm}$ divisions and the experimenter spoke quietly into a tape recorder every time the teat moved from one division to another. The tape recordings were subsequently analysed with the aid of a stop watch to give a continuous record of the changing rotation of the udder throughout the test period.

Four of the sows were tested for rotation of the mammaries in response to stimulation of the upper and lower rows of teats. At the beginning of the test the experimenter rubbed the three most anterior teats of the upper row for 25 to 65 seconds (until the rotation of the udder had appeared to stop), and then rubbed 
the corresponding teats of the lower row for a similar time. This was repeated until each row had received four to eight such stimulations. A signal was spoken into the tape recorder every time the stimulation changed.

For the remaining four sows, stimulation was given in turn to each of the teats of the upper row (except the third or fourth teat which was being used to measure the rotation of the mammaries). The recording of the degree of rotation was begun before the teats were stimulated. Then one of the teats was rubbed between the thumb and index finger for 36 to $120 \mathrm{sec}$ (until the rotation of the udder had subsided). Stimulation was then stopped for about $15 \mathrm{sec}$, and then began again on a different teat. Each teat received two such stimulations with a random order determining the sequence in which the teats were rubbed. Spoken signals were used to indicate the beginning and end of each stimulation.

Fig. 2. The average patterns of rotation of the udder, expressed as the mean number of divisions through which the udder moved, for four different sows when the upper and lower rows of teats were stimulated alternately. Arrows pointing upward indicate the beginning of stimulation of the upper teats; those pointing downward indicate the beginning of stimulation of the lower teats. Results are averaged over four to eight stimulations for each sow.

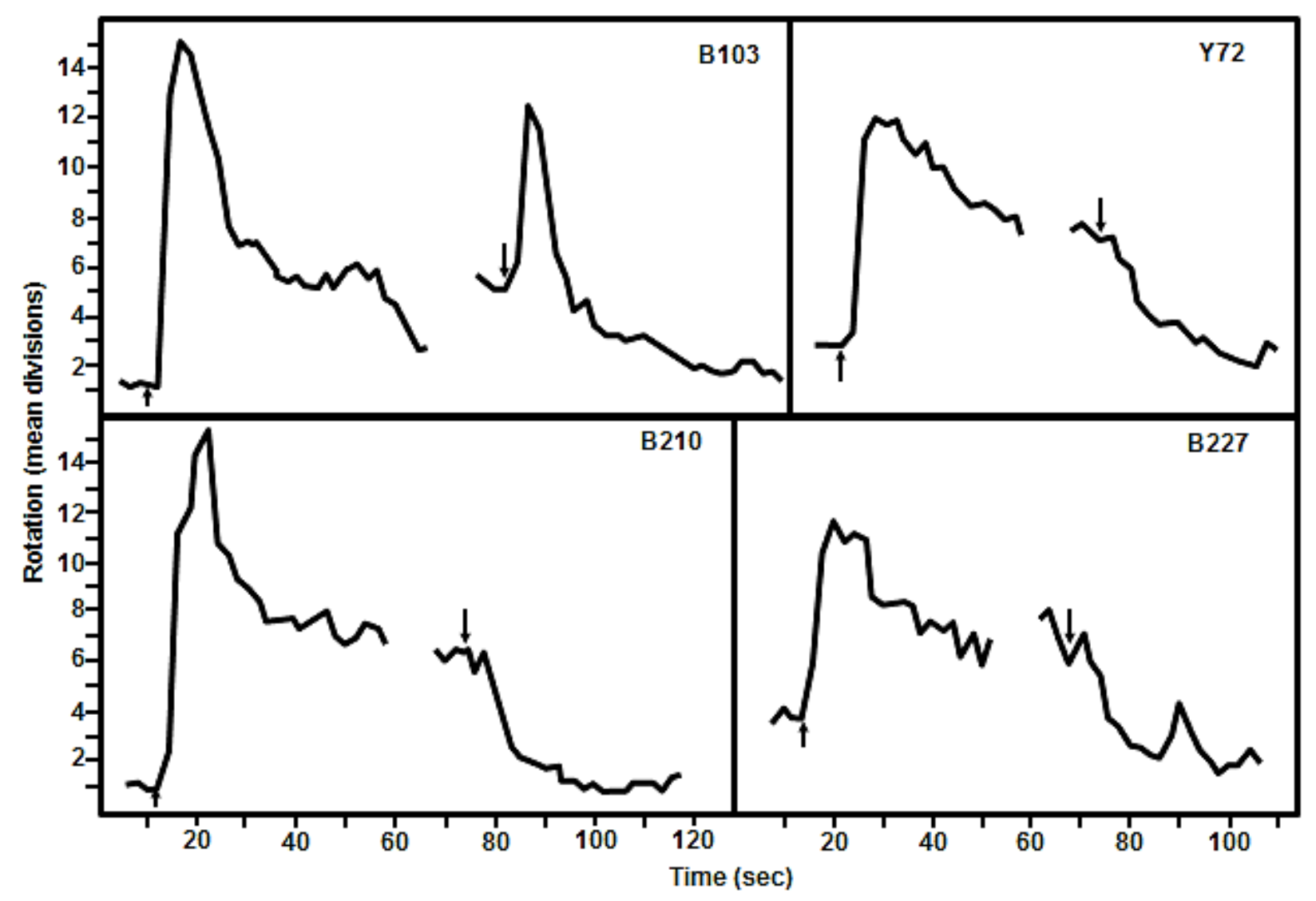

Results.

Fig. 2 shows the average patterns of rotation of the udder for the four sows which were rubbed alternately on the upper and lower teats of the three most anterior pairs. For all four sows, stimulation of the upper row of teats caused a marked upward rotation of the udder, which then declined as the rubbing continued. Three of the sows showed a substantial downward rotation of the udder when stimulation of the lower 
teats began. The remaining sow gave a brief but clear upward rotation when stimulation changed from the upper to the lower teats, but then rotated the udder downward as rubbing of the lower row continued.

The results of the other four sows appear in Fig. 3 which shows the average amount of rotation of the udder elicited by stimulation in turn of the different teats of the upper row. Although there were differences between sows in the overall amount of rotation, all the animals rotated the udder most when the more anterior teats were stimulated.

\section{OBSERVATIONS ON JUVENILE MALES}

\section{Method.}

Four hogs (castrated males) were taken from a large group at about 12 weeks of age, and were housed for an experimental period of 45 days in two identical pens each measuring about $3 \times 4 \mathrm{~m}$. During the first 15 days, pig 1 was kept alone in one pen while pigs 2, 3 and 4 were housed together in the other. Then pig 1 was returned to the group, and pig 2 was housed alone for 14 days, and so on until each pig had had a period of individual housing of 8 to 15 days.

Fig. 3. The average amount of rotation of the udder, expressed as the mean number of divisions ( \pm SE) through which the udder moved, in response to stimulation of the individual teats of the upper row. Teats are numbered from anterior (1) to posterior (7). Only one of teats 3 and 4 was stimulated with each sow, since the position of one of them was used for recording the amount of rotation.

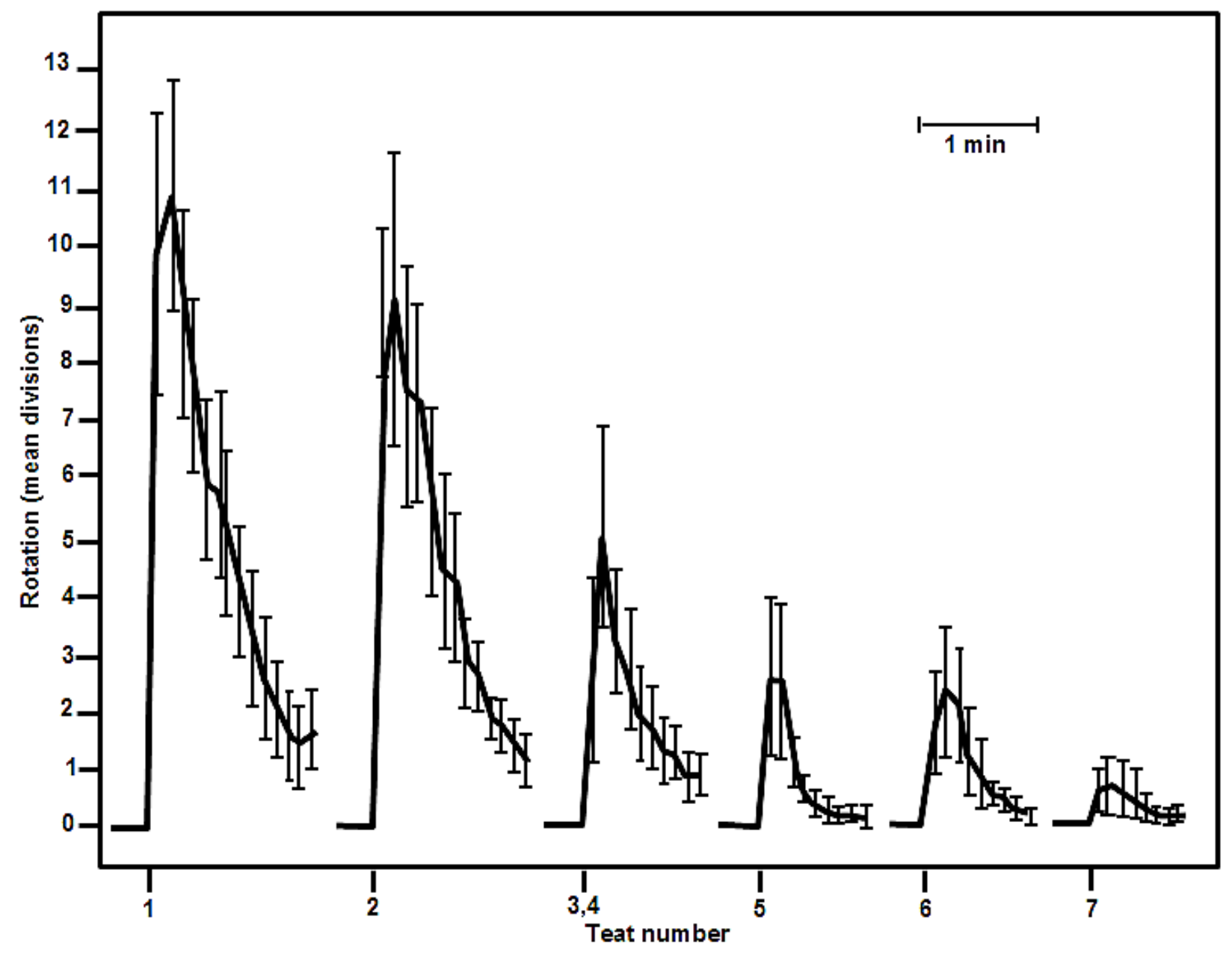


Once a day throughout this period, usually 5 days per week, the experimenter entered both pens for about 10 min and attempted to approach the pigs and rub their bellies by hand. Written notes were made of the animals' reactions, particularly of all instances of lying down, assuming the nursing posture, and rhythmic grunting. These three elements together were called a "complete response" to the stimulation.

Each pig was studied further during its period of individual housing after it had begun to give the complete response to manual stimulation of the belly. On 2 or 3 consecutive days, a tape recording was made of the grunts of each pig for a total of 320 to $640 \mathrm{sec}$ while the experimenter rubbed alternately the anterior or the posterior teats in successive 10-sec periods. In analysing the recordings, the number of grunts was counted in the first $8 \mathrm{sec}$ of each interval and the stop clock was reset in the remaining $2 \mathrm{sec}$. On another day rotation of the belly was measured, using the curved metal ruler as described above for the sows, while the experimenter rubbed alternately the upper or the lower teats of the anterior teat pairs. In addition an attempt was made to measure the rotation of the belly when only the posterior teats were stimulated.

Results.

During the first few days the pigs generally avoided contact with the experimenter. By day 4, however, this reaction had waned so that it was possible to rub the bellies of all animals, frequently while they were feeding or gnawing at the experimenter's boots. The animals' responses to this stimulation appeared to depend on the housing condition. During days 1 to 15 the three group-housed pigs never lay down in response to the stimulation whereas the individually-housed pig 1 gave the complete response of lying, assuming the nursing posture, and grunting rhythmically on day 3 and on every subsequent day. Similarly pigs 2 and 3 began to give the complete response on their 3rd and 4th days of social isolation respectively, and they continued so to respond on virtually all subsequent days. Only pig 4 began to give the complete response (on day 31) while still group-housed. In all four cases, once the pig had first given the complete response it rarely failed to give a similar response on all remaining days of the experiment, even after it had been returned to group housing.

All four pigs gave distinctly more grunts during stimulation of the anterior, compared with the posterior, part of the belly. Table 1 shows the mean $( \pm S E)$ number of grunts in the 8-sec intervals given by each pig during the two types of stimulation.

TABLE 1. The mean ( \pm SE) number of grunts per 8 sec given by the juvenile male pigs when the anterior and posterior ends of the belly were rubbed alternately

\begin{tabular}{|cccc|}
\hline Pig & Anterior & End of Udder & $\boldsymbol{P}^{*}$ \\
\hline 1 & $9.6 \pm 0.6$ & Posterior & $<0.001$ \\
2 & $10.7 \pm 0.5$ & $4.4 \pm 0.5$ & $<0.001$ \\
3 & $6.1 \pm 0.4$ & $1.6 \pm 0.2$ & $<0.001$ \\
4 & $10.7 \pm 0.5$ & $3.3 \pm 0.2$ & $<0.001$ \\
\hline
\end{tabular}

* Statistical comparison by Student's $t$ test for paired comparisons.

The animals also had a clear tendency to rotate the belly toward the stimulation when the upper and lower rows of teats were rubbed alternately. Fig. 4 shows the pattern of rotation for pigs 1, 2 and 4 . Pig 3 showed similar behaviour, but terminated the test prematurely on two consecutive days by rolling onto its belly when only the lower row of teats was stimulated. Similarly it was not possible to compare the effect of stimulation of the anterior and posterior teats on rotation of the udder, because the pigs would not usually remain lying down for more than 15 or $20 \mathrm{sec}$ when only the posterior teats were rubbed. 


\section{OBSERVATIONS ON PIGLETS}

Method.

This study was suggested by the observation that sleeping piglets sometimes assume the nursing posture when their bellies are stroked lightly by hand. In order to examine this reaction more systematically, and to determine whether it is specific to stimulation of the belly rather than any slight disturbance of the animal, 163 piglets from 37 litters were tested in the following way.

Five occasions were chosen when several litters of ages ranging from 1 to 6 weeks were available in the same room. The experimenter waited until a piglet was seen lying with its eyes closed, and positioned in such a way that the upper row of teats and the back could both be stroked by hand without hindrance. Once a piglet had been chosen a coin was tossed, and depending on the result of the toss the experimenter stroked lightly either the belly or the back of the animal. A record was made of the piglet's reactions including rotating the belly upward, pushing the head back, raising either of the upper legs, and the sudden straightening and thrusting back of the upper foreleg. Stimulation normally lasted $10 \mathrm{sec}$, but in cases of disturbance or ambiguous response by the piglet, stimulation was continued for up to $20 \mathrm{sec}$. If the piglet displayed none of the behavioural elements scored, the experimenter re-tested the animal by stroking the part which had not been stroked in the original test (belly or back), and recorded the piglet's behaviour in the same way.

The 163 piglets comprised 79 males and 84 females, with 77 stroked first on the belly and 86 first on the back as determined by the toss of the coin. Of these, 35 responded with one or more of the behavioural elements, and the remaining 128 were re-tested with the other type of stimulation.

Results.

The three main responses of the piglets were rotating the belly $(B)$, pushing back the head $(H)$ and moving the legs (L). These behavioural elements sometimes occurred alone and sometimes in combination with one or both of the other elements, giving seven possible responses. Fig. 5 shows the percentage of piglets which gave each of these responses to (a) stroking the back during the original test and the re-test combined, (b) stroking the belly in the original test, and (c) stroking the belly in the re-test. Rotation of the belly was the most common reaction when the belly was stroked. This element occurred by itself, in combination with raising the foreleg, and in combination with both of the other elements. Only occasionally did rotation of the belly occur in combination with pushing the head back unless the foreleg was raised. The movements of the head and leg rarely occurred individually or together if the belly was not rotated.

A total of 40 piglets gave movements of the legs. Of these, 10 merely raised either or both of the upper legs clear of the floor, while in 30 cases the upper foreleg was straightened and thrust backward.

Stroking of the back elicited a much lower frequency of positive responses, and the rotation of the belly was not the most common response in these cases (Fig. 5). Furthermore stroking the back usually elicited only single elements occurring individually, whereas stroking the belly often resulted in two or three elements in combination. For statistical comparison the pigs were classed as having responded or not, ignoring the number and type of elements displayed. The $x^{2}$ test showed that more pigs responded to stroking of the belly than of the back in both the original test and the re-test $(P<0.01$ in both cases). The $\mathrm{X}^{2}$ test also showed that relatively more males than females responded to stroking of the belly in the original test and the re-test combined $(P<0.05)$. 
Fig. 4. The average patterns of rotation of the belly, expressed as the mean number of divisions through which it moved, for three juvenile male pigs when the upper and lower rows of teats were stimulated alternately. Arrows pointing upward indicate the beginning of stimulation of the upper teats; those pointing downward indicate the beginning of stimulation of the lower teats.

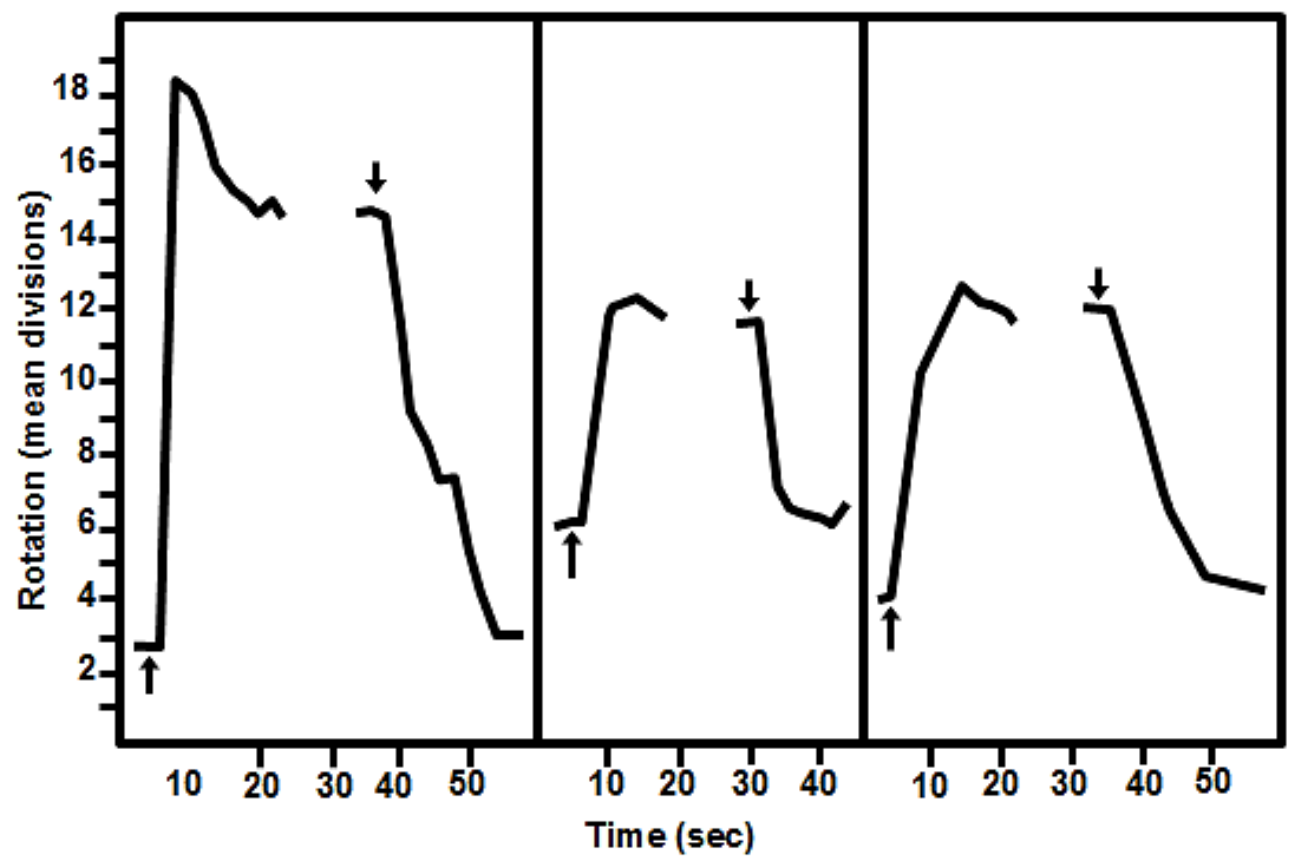

Fig. 5. The percentage of piglets which responded with rotation of the belly (B), pushing back of the head (H), movements of the legs (L) or combinations of these elements, when gentle rubbing was applied to their backs (top), bellies (middle), or to their bellies after they had not responded to stimulation of the back (bottom).

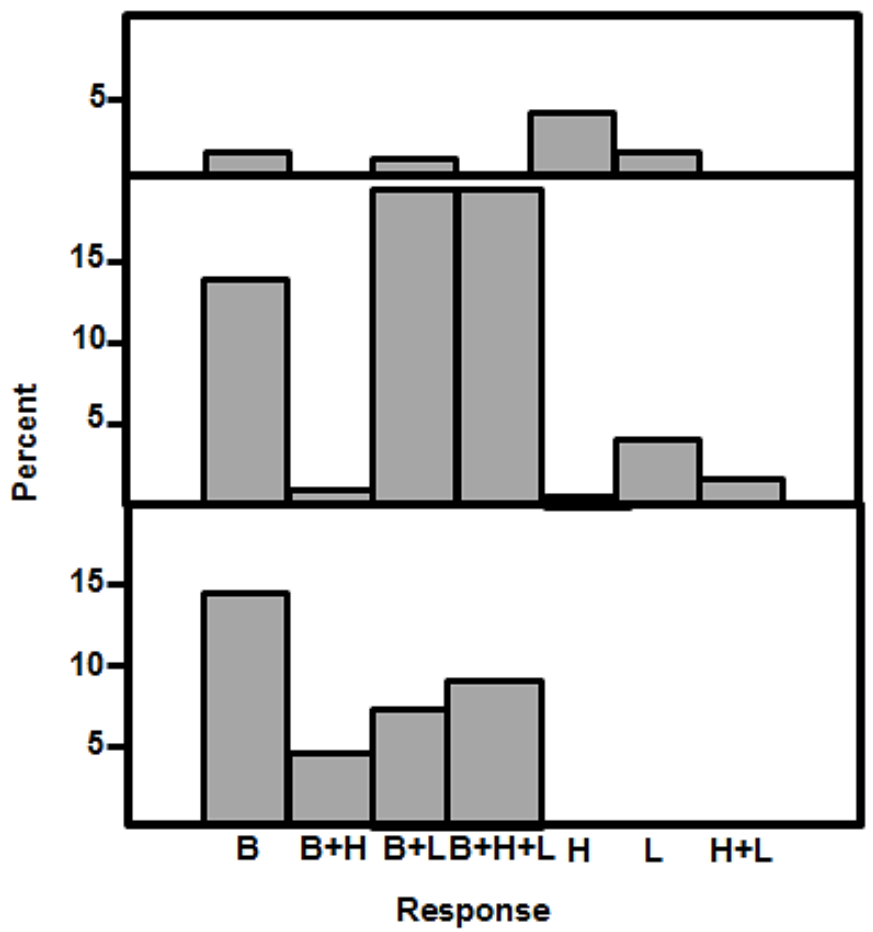




\section{DISCUSSION}

One elementary point made by these experiments is that the nursing posture and associated rhythmic grunting is not a response which develops during pregnancy nor which is confined to the adult female. Rather, juvenile males under appropriate conditions show the full pattern of behaviour as seen with pregnant sows, and even suckling piglets often assume the nursing posture when their bellies are rubbed during periods of inactivity. While the matter has not been studied systematically, it is likely that these piglets, too, would give rhythmic grunts if their bellies were rubbed under suitable conditions; in unpublished studies it had been noted that rhythmic grunts are sometimes given by early-weaned piglets when their bellies are nosed by litter-mates.

\section{Conditions for assuming the nursing posture}

Although the nursing posture was commonly elicited by rubbing an animal's belly, many of the pigs did not behave in this way the first time that the stimulation was applied. With repeated attempts, however, all of the juvenile males and almost all of the sows came to give the complete response including rhythmic grunting; and once an animal had so responded, it generally continued to give the full reaction thereafter. Presumably this represents, at least in part, the waning with repeated exposure of any initial strong reaction to the experimenter and the procedure. This conclusion is reinforced by the fact that the sows which gave a placid initial reaction to the experimenter's first approach were particularly likely to assume the nursing posture the first time their bellies were rubbed.

In addition to its obvious function in maternal behaviour, the nursing posture also occurs as a response of growing pigs to "grooming" or "nosing" of the belly by other animals, an activity which is particularly common when acquainted pigs are reunited after a time apart. EWBANK \& MEESE (1971) removed pigs from their home group and returned them after 5 to 35 days of social isolation. The returned animal was frequently nosed and licked around the head, ano-genital region and along the teat line. Similar behaviour was observed by FRASER (1974) when former pen-mates were re-grouped after 1 to 25 days of separation. In both of these studies, some of the animals responded to this nosing by lying down, exposing the belly and often holding one leg in the air. As with the response to manual stimulation of the udder, the probability that this behaviour would occur was related to other aspects of the pigs' reactions to the animal performing the nosing in the experiment of EWBANK \& MEESE only the top-ranking pigs lay down when nosed; and in FRASER's study, lying down in response to nosing was seen only with pigs which were observed not to be bitten by the partner.

It may be relevant that in both of the studies just mentioned, the animals which lay down in response to nosing of the belly had just had a period of isolation from tactile contact with other pigs. In the experiment on juvenile males in the present paper, individual housing appeared to increase the speed with which the animals acquired the response, but it is not clear how social isolation had this effect. It may simply have altered the pigs' overall reaction to the experimenter, although there were no other obvious behavioural differences to suggest this. Alternatively, depriving the animals of contact with other pigs may have made them more responsive to tactile stimulation from other sources. The pregnant sows in the present experiments were also housed out of direct contact with other animals; this may have contributed to the readiness with which they responded to manual stimulation of the udder.

Some unpublished observations on early-weaned piglets suggest one further factor which may affect willingness to assume the nursing posture. When belly-nosing (or "navel-sucking") first breaks out in an early-weaned litter the animals appear often to lie down and assume the nursing posture in response; but 
if the nosing becomes rough or is extremely frequent or prolonged the animals appear to stop lying down in response, and may even bite the litter-mate performing the nosing. Perhaps a certain level of stimulation of the udder is rewarding at a given age, but in some situations the upper limit is passed and the stimulation becomes aversive.

\section{Anterior and posterior teat stimulation.}

Previous work has shown that stimulate on is more effective if directed to the anterior than to the posterior teats, both in eliciting rhythmic grunts from pregnant and lactating sows, and in triggering the milk ejection reflex (FRASER, 1973, in press). The present study extends this finding by showing that directed rotation of the udder is also elicited more effectively by anterior teat stimulation of pregnant sows. Furthermore a similar observation was made for the rate of grunting by juvenile male pigs. This latter finding indicates that the difference in sensitivity cannot be due solely to some factor associated with lactation -- for instance that the anterior teats might be more engorged with milk. Rather, the phenomenon may be a basic feature of the nervous system of pigs, and perhaps of other polytocous species as well (see CROSS, 1961). This helps to explain the strong tendency of piglets to occupy the anterior teats preferentially as discussed by FRASER (1973).

\section{Elements of the nursing posture.}

The sows and juvenile males generally gave a sustained response to stimulation of the udder involving rotation of the udder, pushing back the head, and movements of the legs including holding one leg in the air and sometimes straightening the forelegs and pushing them back forcibly. The sleeping piglets, however, generally gave a much attenuated response. Of the various motor elements only the rotation of the udder commonly occurred alone; the movements of the head and legs were rarely seen except in combination with the udder response. This suggests that rotation of the udder is the primary response of the pattern, the other components appearing mainly as elaborations.

Rotation of the udder is of obvious importance for exposing both rows of teats during a nursing episode, but it is not clear why the response sometimes fails in this respect. When the nursing sow is lying on one side, the upper row of teats generally appears to receive more stimulation (further evidence from GILL \& THOMSON, 1956). This would encourage the advantageous response of rotating the udder upward. Failure of the behaviour might be caused in some cases by an unusually large amount of stimulation of the lower teats, as well as by some possible inherent aspect of the particular sow such as an especially heavy udder or poor muscular control.

The other motor elements are of less obvious functional significance, particularly the sudden backward movement of the forelegs which sometimes batters the piglets away from the important anterior teats. (However this may force the young to re-arrange themselves on the udder if they are competing noisily for position). But perhaps the clue as to the involvement of the head and leg movements is not so much in their own functional significance for nursing as in the possible origin of the whole nursing posture. Casual observation suggests that pigs sometimes assume the nursing posture spontaneously as a way of stretching the body, especially after sleep. Perhaps this pattern of stretching was common among ancestors of the modern pig, and came to be elicited by stimulation of the udder because of the obvious advantage of full exposure of the teats for nursing. Possibly, then, the other components of the stretching pattern are not completely emancipated from the rotation of the udder, even in the new context of nursing. If the elaborate nursing posture of the pig is, in essence, an adapted form of stretching, this would help to explain why the response is so readily elicited in pigs of both sexes from a very early age.

\section{SUMMARY}


The nursing behaviour of the sow commonly involves upward rotation of the udder, movements of the head and legs, and rhythmic grunting. Aspects of this behaviour were studied in several experiments with pregnant females, juveniles males, and suckling piglets. Many pregnant females lay down and assumed the nursing posture when their udders were first rubbed by hand. Those which initially appeared agitated in the experimenter's presence often failed to do so until after some habituation to the procedure. When the upper and lower rows of teats were rubbed alternately, the udder was usually rotated toward the stimulation. This rotation, like the rate of grunting and milk ejection, was greatest when the most anterior teats were stimulated. Juvenile male pigs showed very similar behaviour. When housed alone they lay down in response to manual stimulation of the belly, but only after some habituation to the experimenter. They rotated their bellies toward the stimulation, and gave most grunts in response to stimulation of the anterior teats. Sleeping piglets often gave an attenuated form of the nursing posture when their bellies were rubbed gently. Rotation of the belly was the most common response, with the movements of the head and legs apparently occurring as elaborations.

\section{REFERENCES}

CROSS, B. A. (1961). Neural control of lactation. -- In: S. K. KON \& A. T. COWIE (Ed), Milk: The mammary gland and its secretions, Vol. 1. London: Academic Press.

EWBANK, R. \& MEESE, G. B. (1971). Aggressive behaviour in groups of domesticated pigs on removal and return of individuals. -- Anim. Prod. 13, p. 685-693.

FRASER, D. (1973). The nursing and suckling behaviour of pigs. I. The importance of stimulation of the anterior teats. -- Br. vet. J. 129, p. 324-336.

---- (1974). The behaviour of growing pigs during experimental social encounters. -- J. agric. Sci., Camb. 82 , p. 147-163.

---- (1975). The nursing and suckling behaviour of pigs. III. Behaviour when milk ejection is elicited by manual stimulation of the udder. -- Br. vet. J. 131, p. 416-426.

----- (in press). The nursing and suckling behaviour of pigs. IV. The effect of interrupting the suckling stimulus. -- Br. vet. J.

GILL, J. C. \& THOMSON, W. (1956). Observations on the behaviour of suckling pigs. -- Anim. Behav. 4, p. $46-51$.

RINGARP, N . (1960). Clinical and experimental investigations into a post-parturient syndrome with agalactia in sows. -- Acta agric. Scand., Suppl. 7. 